\title{
Optimal generation capacity mix in microgrid to meet demand
}

\author{
Virendra Sharma ${ }^{1}$, Piyush Kumar Choubey ${ }^{2}$, Amit Kumar ${ }^{3}$, Lata Gidwani ${ }^{4}$ \\ ${ }^{1,2,3}$ Department of Electrical Engineering, Arya College of Engineering and IT Jaipur, India \\ ${ }^{4}$ Department of Electrical Engineering, Rajasthan Technical University, Kota, India
}

\begin{tabular}{l} 
Article Info \\
\hline Article history: \\
Received Oct 13, 2020 \\
Revised Apr 10, 2021 \\
Accepted Jun 18, 2021 \\
\hline Keywords: \\
Generation capacity mix \\
Hybrid renewable energy \\
source \\
Micro-grid \\
Solar PV-generator \\
Utility network load
\end{tabular}

\begin{abstract}
This paper presents an approach for optimal generation capacity mix to fulfill future power demand using a micro-grid model which is operated in both the on-grid and off-grid modes. This is achieved using the solar photovoltaic (PV) system, fuel-cell, and battery energy storage system (BESS) with and without the grid-connected mode. Different control approaches and optimal size of the generators are presented. Proposed micro grid with solar PV system, solid oxide fuel cell (SOFC) and back scattered electron detector (BESD) is tested for different operational scenarios of loads. Comparative index of performance (CIP) is introduced to indicate effectiveness of the micro-grid operations in the off-grid mode. This is based on difference in the total harmonic distortions (THD) in both the on-grid and off-grid modes. This is established that CIP indicates that the micro-grid works efficiently in the both the on-grid and offgrid modes during the simulated events of the switching ON/OFF the loads at different test conditions. The optimal generation mix successfully met the load demand with and without grid having conventional generation.
\end{abstract}

This is an open access article under the CC BY-SA license.

\section{Corresponding Author:}

Virendra Sharma

Department of Electrical Engineering

Arya College of Engineering and IT

Jaipur, 302028, Rajasthan, India

Email: vsharmakiran@gmail.com

\section{INTRODUCTION}

Power generation from the renewable energy sources (RES) in a hybrid power system, where different types of RE generators are interfaced, is affected by different types of the operational and faulty events. This may result in interruption of power flow and voltage profile in the utility network. Sometimes, such events may also lead to blackouts as well as generation of high transients [1]. This becomes more pronounced during micro-grid operations. The power control of hybrid renewable energy sources (HRES) based power system is formed to meet future energy demand. This is achieved by integrating solar PV plant, solid oxide fuel cell (SOFC) stack, battery energy storage system (BESS), and electrolyzer in the form of hydrogen tanks used for fulfilling the future energy demand and enhances the power quality [2].

The solar PV generator and SOFC both have positive healthy environment such as carbon free and inexhaustible, promising green power source and it is effective to provide sufficient power connected to the utility network. The demerits such as slow dynamics and gas starvation problems of SOFC fails in providing fast response and also face load following problems [3]. However, an integration of SOFC with complementary device such as back scattered electron detector (BESD) can solve these problems in both the grid-connected mode and off-grid micro-grid mode. Solar PV generation technology is considered as one of the key solution for pure and clean technologies to generate electricity, but it is depends on weather conditions, has low efficiency and high initial cost [4]. As a result of its low generation efficiency it is nearly impossible to exploit 
the maximum solar power coming out of PV array therefore at its highest energy conversion output it leads to the operational failure of the device [5].

As the irradiation and ambient temperature have their effects on the generation of maximum power. This inspection gives a brief comparison among the realization of different maximum power point tracking (MPPT) methods and results a new MPPT technique with improved capability than the existing ones [6]. Different techniques are reported in literature which suggests the hybrid operations of the RE sources to meet future energy demands. According to Chawda et al. [7], proposed a method for application of solar PV plant, solid oxide fuel cell and electrolizer with energy storage device for power supply to utility grid in hybrid power network (HPNW) model. The PV generator plant is used for meeting the load demands of consumers.

The hydrogen power generation technology is utilized to ensure long-term energy balance as well as supply to industrial consumers. The battery storage system is used as a backup to care of the load when any disturbance occurs at grid. The dynamic performance of a hybrid power generation system is tested under different solar radiation, temperature and different load conditions during simulation for a period of 3 second. In [8], authors introduced a research work based on distribution of the active and reactive power for load with and without grid application using hybrid RE sources. This method is found to be effective in improving performance of the utility network associated with renewable energy generation during with grid and without grid application. A study on impact of grid disturbances on output of solar PV plant is discussed. The power quality and protection issues become serious during integration of the RE sources to form the micro grids and hybrid grids which can be operated in the on-grid as well as off-grid modes.

A method to investigate the power quality (PQ) disturbances and identification of various events in distribution utility network interfaced with the wind generation using the stockwell transform (ST) and fuzzy c-means clustering (FCM) is reported in [9], [10]. PQ assessment and identification of events in the RE sources based hybrid power system is detailed in [11]. PQ assessment in distribution system interfaced with solar energy using an approach based on ST and FCM is reported in [12]. A study for recognition of faults in the grid with renewable energy penetration is reported in [13]-[16].

Main contributions of this paper are summarized by the following points:

- A micro-grid is designed to reduce the burden on grid and also to maximize the performance of PV, BESD and SOFC in both the on-grid and off-grid modes. The optimal generation mix is achieved to meet the future load demand.

- The dynamic power flow controllers are designed for the SOFC, solar PV system and BESD. It supervises and manages all the energy sources and power flow to meet the load demands during different operating scenarios.

- According to this strategy PV generator and SOFC has the priority in meeting load demand. The BESD is utilized as a complement and/or backup storage device to improve the low performance of the Solid oxide FC during transient conditions, whereas an electrolizer is used as a dump load to generate hydrogen for SOFC during surplus power. The proposed micro-grid is synchronized to the grid and residential load through electronic converters such as DC-DC converter and AC to AC converter in order to enhance the reliability, stability and continuity of power supply.

- At the end, a comparative index of performance (CIP) is introduced to indicate effectiveness of the microgrid operations in the off-grid mode. This is based on the difference in the total harmonic distortions (THD) in both the on-grid and off-grid modes.

\section{DESIGN OF PROPOSED TEST MICRO-GRID SYSTEM}

Test micro-grid used for the proposed study has been designed by integrating the solar PV plant, SOFC and battery energy storage device to a common DC bus. The DC to DC converters are used to integrate the solar PV system, BESD and SOFC to the DC bus which is maintained at $814 \mathrm{~V}$. This network is implemented as micro-grid to fulfil power demand of the consumer using green and clean energy. This is established that the proposed test micro-grid effectively works during the events of switching on/off the resistive and reactive loads in both the on-grid and off-grid modes. Test micro-grid with all components such as solar PV system, SOFC, BESD, utility grid, converters, DC bus and AC bus are detailed in the Figure 1. The utility grid is connected to the AC bus which is designated as generator bus or utility bus. This bus is maintained at a voltage of $240 \mathrm{~V}$ and used for supplying the power to loads. A DC-AC inverter is connected between the DC bus and AC used convert the $820 \mathrm{~V} \mathrm{DC}$ power to $240 \mathrm{~V}$ AC power. This point is considered as the point of common coupling (PCC). The power will be supplied from the DC bus to the AC bus as per requirement of the loads. The loads integrated to the AC bus of test micro-grid are detailed in the Table 1. The solar PV system, SOFC, BESD and converters used in the test micro-grid are detailed in the following subsections. 


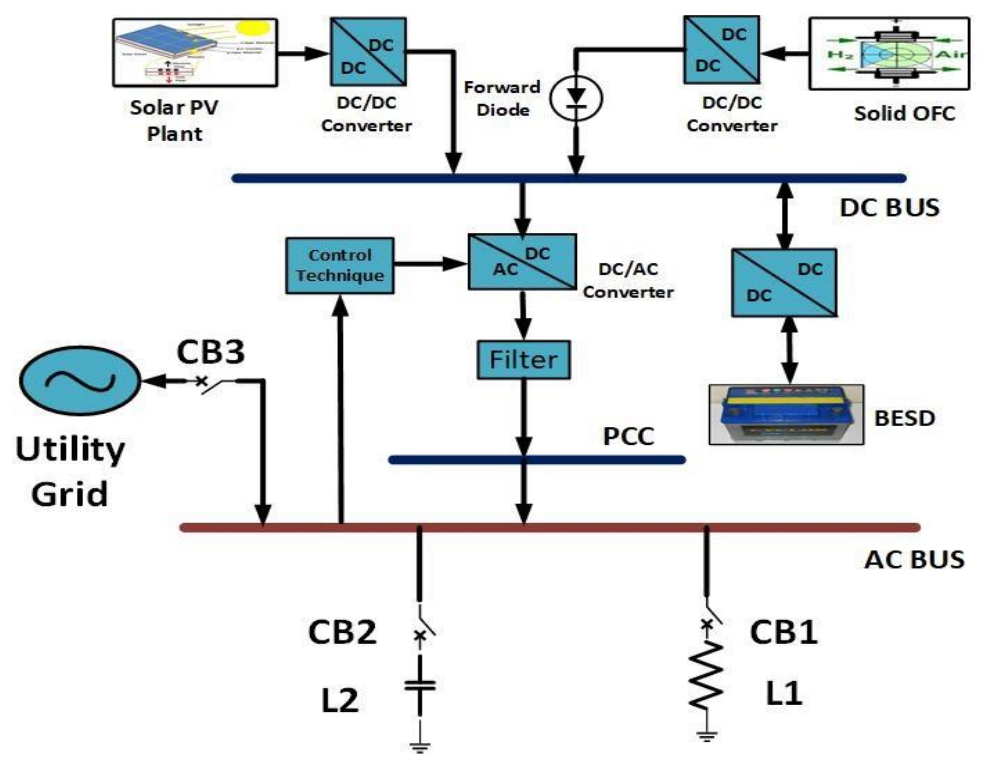

Figure 1. Test micro-grid used for the study

Table 1. Loading status of test micro-grid

\begin{tabular}{cll}
\hline Load Symbol & Type of Load & Load Value \\
\hline L1 & Resistive Load & $15 \mathrm{~kW}(5 \mathrm{~kW}$ on each phase $)$ \\
L2 & $\begin{array}{l}\text { Capacitive } \\
\text { Load }\end{array}$ & $5 \mathrm{kVAr}$ \\
&
\end{tabular}

\subsection{Solar energy conversion system}

The solar energy conversion system of maximum rated capacity of $10 \mathrm{~kW}$ used for the proposed study and consisting of solar photovoltaic cells is interfaced to test system on DC bus using a dc-dc converter. This solar PV generation system can generate $10 \mathrm{~kW}$ using the gain while without gain it can generate power up to $6 \mathrm{~kW}$. The output direct current voltage from solar PV generator is $672 \mathrm{~V}$ with the help of MPPT point which is increased to $814 \mathrm{~V}$ dc using a boost-converter (chopper). This generated power is fed to DC bus maintained at $814 \mathrm{~V}$. The solar energy conversion system used in the study has a rating of $10 \mathrm{~kW}$. The power is delivered to load at voltage level of $140 \mathrm{~V} \mathrm{AC}$. Details of parameters used in test network are provided in Table 2. A detailed description of the solar PV system and associated DC-DC converter used for the proposed study is available in [10]-[12].

Table 2. Solar PV parameters of test system

\begin{tabular}{cll}
\hline S. No. & Parameter of Solar PVECS & Value \\
\hline 1 & Current at $I_{M P P}(\mathrm{~A})$ & 7.612 \\
2 & Short circuit current $I_{S C}(\mathrm{~A})$ & 8.27 \\
3 & Rated power before gain $P_{p v}(\mathrm{~kW})$ & 6 \\
4 & Rated power after gain $P_{p v}(\mathrm{~kW})$ & 10 \\
5 & Open circuit voltage $V_{O C}($ Volt $)$ & 406 \\
6 & Maximum power point voltage $V_{m p p}($ volt $)$ & 336 \\
7 & Insolation to current gain & $8.01 / 1000$ \\
8 & Irradiance constant & 1000 \\
9 & Series resistance $R_{s e}(\Omega)$ & $0.055^{*} 11$ \\
10 & Parallel resistance $R_{S h}(\Omega)$ & 550 \\
\hline
\end{tabular}

\subsection{Solid oxide fuel cell energy conversion system}

A fuel-cell which converts chemical energy using hydrogen and water into the electrical power is used this in study. In the fuel cell, reaction between hydrogen and oxygen takes place to produce water liberating large amount of energy. According to Mahela et al. [13], a SOFC energy conversion system is reported which is considered for the technical parameters. The SOFC used in this study is rated to generate power of $50 \mathrm{~kW}$. This is interfaced to the proposed micro-grid test system on common DC bus using a DC to DC converter 
through a forward diode and a power line. The technical parameters of the solid oxide fuel cell plant used in the proposed work are indicated in the Table 3.

Table 3. Solid oxide fuel cell parameters

\begin{tabular}{cll}
\hline S. No. & Parameter of Solid oxide fuel cell & Value \\
\hline 1 & Absolute temperature $(\mathrm{K})$ & $1273 \mathrm{~K}$ \\
2 & Initial Current $(\mathrm{A})$ & 100 \\
3 & Faraday's constant $(\mathrm{C} / \mathrm{k} \mathrm{mol})$ & $96.487 e^{-6}$ \\
4 & Ideal standard potential $(\mathrm{V})$ & 1.18 \\
5 & Number of cells in series & 450 \\
6 & Ohmic Loss per cell $(\Omega)$ & $3.2813 e^{-0.04}$ \\
7 & Electrical response time $(\mathrm{Sec})$ & 0.8 \\
8 & Fuel processor response time $(\mathrm{Sec})$ & 5 \\
9 & Ratio of Hydrogen to Oxygen & 1.145 \\
\hline
\end{tabular}

\subsection{Battery energy storage device}

Battery energy storage device is the essential part of proposed micro-grid test system which is used to store energy when surplus power is available and supply the loads when there is shortage of power. This will help to maintain uninterruptable power supply to the consumer loads. A brief detail of the BESD used for the study is available in [14]-[17]. The battery system with DC link is integrated to dc bus of the proposed micro-grid test system. The $6.5 \mathrm{Ah}$ capacity of battery storage device is used for exchange of powers on dc bus. The technical values of battery energy storage device used of test system are represented in Table 4 .

\begin{tabular}{cll}
\multicolumn{2}{c}{ Table } & 4. Battery energy storage parameters \\
\hline S. No. & Parameter of Solid oxide fuel cell & Value \\
\hline 1 & Nominal voltage (V) & 300 \\
2 & Rated capacity (Ah) & 6.5 \\
3 & Initial State of Charge (\%) & 60 \\
4 & Battery response Time (sec.) & 30 \\
5 & Type & NMH \\
\hline
\end{tabular}

\subsection{Converters used in the test system}

The DC-DC boost converters are used to integrate the SOFC, Solar PV system and BESD to the DC bus of the micro-grid for obtaining regulated DC power supply. This power is fed to the insulated gate bipolar transistor (IGBT) based inverter. The RE sources like solar and SOFC generator produces dc output power, the voltage of which is changed to common DC bus voltage by the use of DC-DC boost converter. The inverter is based on power electronics device and used to convert a DC input voltage into constant AC output voltage required at grid level as well as utility load at AC bus of the proposed test system [18], [19]. A desirable AC voltage can be obtained by changing the DC input power, which is available on the DC bus with the help of dc to dc converter and maintaining the gain of the inverter constant. The control algorithm reported in [20] is employed for control of the inverter using the voltage and current signals measured at AC bus as the reference values.

\section{PROPOSED POWER OPTIMIZATION APPROACH}

Following are the important steps of the power optimization approach employed in this paper:

- The power in the micro-grid is optimized using the different controls of the SOFC, solar PV system, BESD, and inverter. Power balance between the all the sources and loads is analyzed.

- Voltage and current waveforms recorded on the PCC and DC bus are analyzed to evaluate the performance of the micro-grid in both the on-grid and off-grid modes during.

- The simulated events include the switching on the resistive loads and simultaneous switching on the reactive $\&$ active loads. The events are analyzed in both the on-grid and off-grid modes.

- THD of the voltage at current recorded on the PCC has been calculated. Proposed CIP is used to indicate the effectiveness of the micro-grid operations in the off-grid mode compared to the on-grid mode.

The mathematical relations used for calculations such as voltage, current and power in the proposed microgrid are described in the following subsections. 


\subsection{Calculation of power recorded on PCC}

Power generated by proposed micro-grid and supplied to the AC-bus which is measured at PCC can be computed using (1).

$$
P=\sqrt{3} V_{L} I_{L}
$$

Where, $\mathrm{P}$ is the active power generated by hybrid RE-sources, $V_{L}$ is line to line voltage $\& I_{L}$ is line current. This relation is used to validate the power recorded on the PCC.

\subsection{Calculation of line voltage}

The expression (2) is used to determine the RMS value of voltage $\left(V_{L r m s}\right)$ recorded on the PCC.

$$
V_{\text {Lrms }}=\frac{\mathrm{v}_{\max }}{\sqrt{2}}
$$

Where, $\mathrm{V}_{\max }$ is the maximum value of the voltage which is supplied by the hybrid RE-sources. Performance is evaluated in terms of the THD of this voltage in the on-grid and off-grid modes of operations of the microgrid. THD of voltage is computed using the fast Fourier transform (FFT).

\subsection{Calculation of line current}

The expression (3) is used to calculate and determine the RMS value of current recorded at PCC. This is used to evaluate performance of the micro-grid.

$$
I_{L r m s}=\frac{\mathrm{I}_{\max }}{\sqrt{2}}
$$

Where, $\mathrm{I}_{\max }$ is the maximum value of current. Performance is evaluated in terms of the THD of this current in the on-grid and off-grid modes of operations of the micro-grid. THD of voltage is computed using the FFT.

\section{RESULTS AND DISCUSSION}

Discussion of the simulation results and their analysis are presented in this section. Investigated operational events include switching on the resistive load, and simultaneous switching of the resistive and capacitive load. A circuit breaker (CB) is operated at 0.1 second to perform the event of isolation and integration of the test micro grid to the utility grid. Study is performed in off-grid and on-grid modes with a BESD. Effect of hybrid RE source system to deliver the power in off-grid and on-grid modes and disturbances associated with all events are detailed in the following subsections. Measurement of active power $(\mathrm{P})$ and reactive power $(\mathrm{Q})$ has been made at a point between the $\mathrm{AC}$ bus and $\mathrm{DC}$ to $\mathrm{AC}$ inverter which is designated as PCC.

\subsection{All loads are switched off in off-grid mode}

The test system is operated in the isolated micro grid in off-grid mode to analyze the performance of the power generation sources. All the loads are kept off and micro-grid test system is disconnected from the utility grid. Power generated by the SOFC, power stored by the BESD, power generated by solar PV System and active and reactive power consumed by loads are illustrated in the Figure 2. Figure 2(a) and Figure 2(b) indicate that the $31 \mathrm{~kW}$ and $6 \mathrm{~kW}$ power is supplied by the SOFC and solar PV system respectively. Figure 2(c) indicates that the power absorbed by the BESD is equal to $37 \mathrm{~kW}$.

It is observed from the Figure 2(d) that the power consumed by the load is almost zero and only the loss component appears. Hence, it is established that when the test system is operated in the isolated micro grid in off-grid mode without any load, the power supplied by the SOFC and solar PV system is used to charge the BESD. Hence, the proposed micro-grid system operates efficiently. 


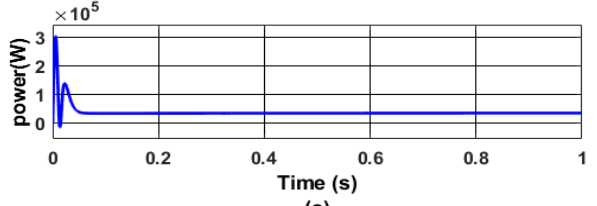

(a)

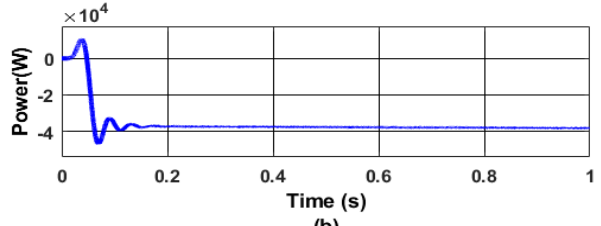

(b)

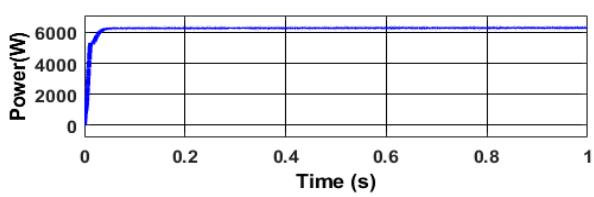

(c)

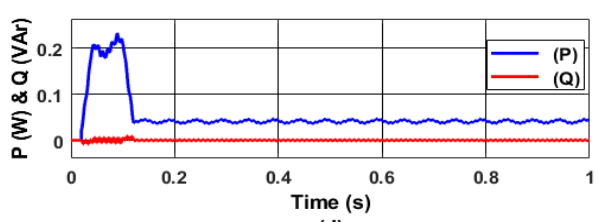

(d)

Figure 2. Micro-grid is operated in off-Grid Mode and all the loads are switched-off: (a) power generated by SOFC, (b) power stored by BESD, (c) power generated by solar PV system, and (d) active and reactive power exchange between the AC-bus and DC-bus

\subsection{Event of switching on the resistive load in off-grid mode}

The test micro-grid is operated in the off-grid mode to analyze the performance. The micro-grid test system is disconnected from the utility grid. A resistive load of $15 \mathrm{~kW}$ ( $5 \mathrm{~kW}$ on each phase) is connected to the $\mathrm{AC}$ bus at $0.1 \mathrm{~s}$ to investigate the effect of load switching on the performance of proposed micro-grid in the off-grid mode. Power generated by the SOFC, power stored by the BESD, power generated by solar PV System and active \& reactive power consumed by the resistive load are illustrated in the Figure 3. Figure 3(a) and Figure (b) indicate that the $45 \mathrm{~kW}$ and $6 \mathrm{~kW}$ power is supplied by the SOFC and solar PV system respectively. Figure 3 (c) indicates that the power absorbed by the BESD is equal to $36 \mathrm{~kW}$. It is observed from the Figure $3(\mathrm{~d})$ that the $5 \mathrm{~kW}$ power on phase-A (total $15 \mathrm{~kW}$ ) is consumed by the restive load. The reactive power exchange is zero because the restive load does not consume the reactive power. Hence, it is established that when the test micro-grid is operated in the off-grid mode in the presence of the load, the power supplied by the SOFC and solar PV system is used to charge the BESD and consumed by the resistive load. Hence, the proposed micro-grid system operates efficiently in the presence of the restive load in the off-grid mode.
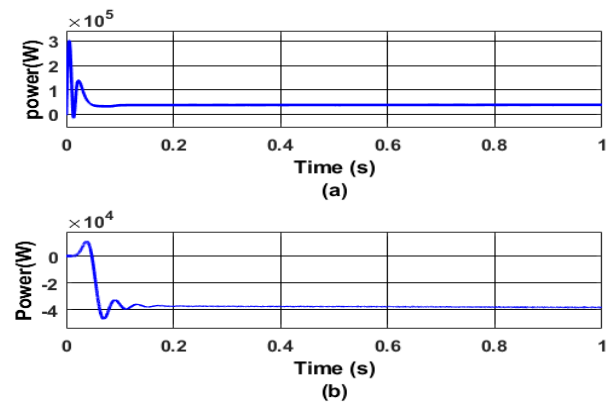

(b)
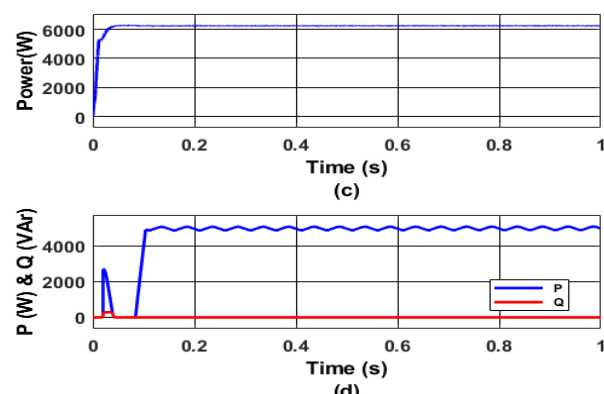

(d)

Figure 3. Micro-grid is operated in off-grid mode during event of switching on the resistive load: (a) power generated by SOFC, (b) power stored by BESD, (c) power generated by solar PV System, and (d) active and reactive power exchange between the $\mathrm{AC}$ bus and $\mathrm{DC}$ bus

The waveforms of voltage measured on the AC bus and current supplied by the micro-grid to the AC bus are detailed in the Figure 4(a) and Figure 4(b) respectively. The root mean square (RMS) value of the current supplied by the micro-grid to the AC bus and DC current to the inverter (HRES current) are described in the Figure 4(a) and Figure (b) respectively. The transients observed at starting time are due to the start of the simulation. Figure 4(a) illustrates that before switching on the load, there are small transients in the voltage which have been reduced after the resistive load is switched on at 0.1s. Figure 4(b) illustrates that current is zero before the event of switching on the resistive load and it becomes finite after this event. Further, it is also observed that the current waveform is uniform. Figure 4(c) illustrates that the current supplied by the microgrid to the AC bus and DC current to the inverter (HRES current) have constant values with minimum disturbances in the off-grid. Hence, it can be concluded that in the off-grid mode the proposed micro-grid works 
efficiently to supply the loads and additional power is absorbed by the battery which can be used as and when required to supply the load.

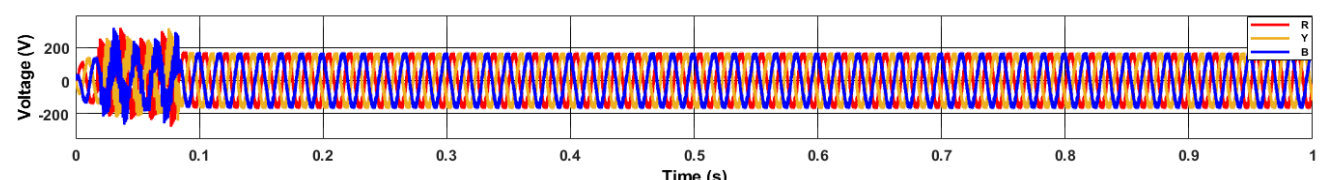

(a)
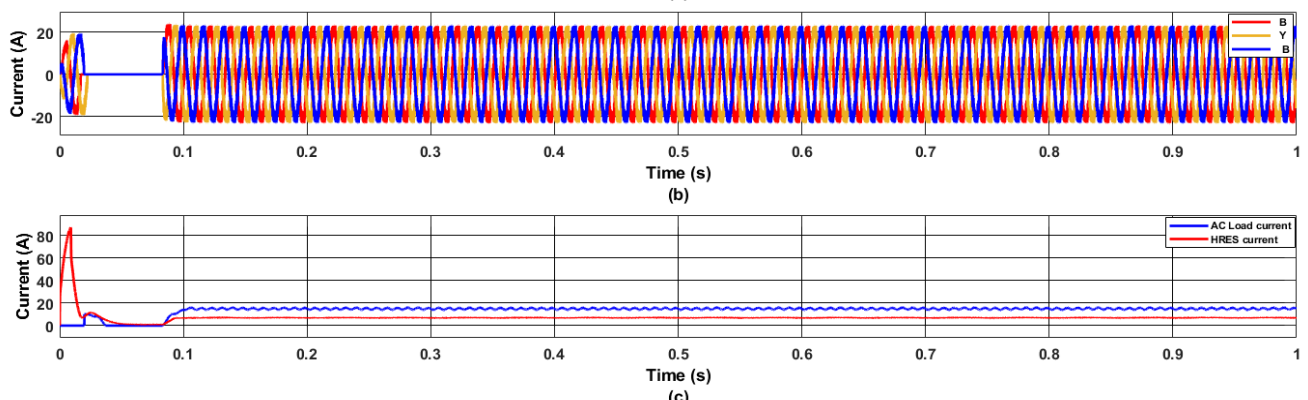

(c)

Figure 4. Micro-grid is operated in off-grid mode during event of switching on the resistive load: (a) voltage signal profile, (b) current signal, and (c) RMS value of current and HRE source current

\subsection{Event of switching on the resistive load in on-grid mode}

The test micro grid is operated in the on-grid mode to analyze the performance. The micro-grid test system is kept connected to the utility grid. A resistive load of $5 \mathrm{~kW}$ is connected to the AC bus at $0.1 \mathrm{~s}$ to investigate the effect of load switching on the performance of proposed micro-grid in the on-grid mode. Power generated by the SOFC, power stored by the BESD, power generated by solar PV System and active \& reactive power consumed by the resistive load are illustrated in the Figure 5.

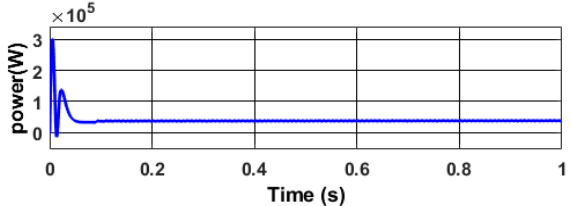

(a)

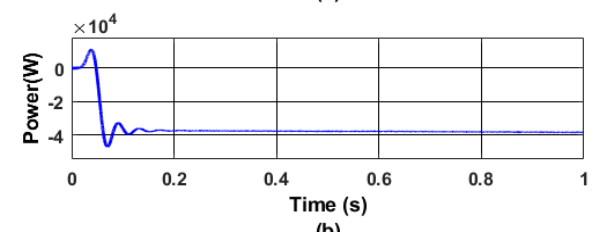

(b)

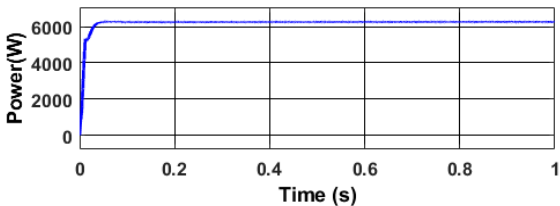

(c)

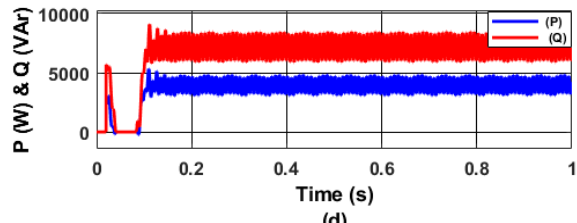

(d)

Figure 5. Micro-grid is operated in on-grid mode during event of switching on the resistive load: (a) power generated by SOFC, (b) power stored by BESD, (c) power generated by Solar PV System, and (d) active and reactive power exchange between the $\mathrm{AC}$ bus and DC bus

Figure 5(a) and Figure 5(b) indicate that the $45 \mathrm{~kW}$ and $6 \mathrm{~kW}$ power is supplied by the SOFC and solar PV system respectively. Figure 5(c) indicates that the power absorbed by the BESD is equal to $37.5 \mathrm{~kW}$. It is observed from the Figure $5(\mathrm{~d})$ that the $4.5 \mathrm{~kW}$ power (total $13.5 \mathrm{~kW}$ power) is consumed by the resistive load. The reactive power of $7.5 \mathrm{kVAr}$ is also supplied by the filter installed between the DC-AC invert and AC bus. Since, resistive load does not consume the reactive power; hence this reactive power will be supplied to the utility grid. Therefore, it is established that when the test micro-grid is operated in the on-grid mode in the presence of the load, the power supplied by the SOFC and solar PV system is used to charge the BESD and consumed by the resistive load. The balance $1.5 \mathrm{~kW}$ power has been supplied by the utility grid. Hence, proposed microgrid system operates efficiently in the presence of restive load in the on-grid mode. 
The waveforms of voltage measured on the AC bus and current supplied by the micro-grid to the AC bus during event of switching on the resistive load in on-grid mode are detailed in the Figure 6(a) and Figure 6(b) respectively. The root mean square (RMS) value of the current supplied by the micro-grid to the AC bus and DC current to the inverter (HRES current) are described in the Figure 6(a) and Figure 6(b) respectively. The transients observed at the starting time are due to the start of the simulation. Figure 6(a) illustrates that before switching on the load, there are small transients in the voltage which have been reduced after the resistive load is switched on at $0.1 \mathrm{~s}$. Figure 6(b) illustrates that current is zero before the event of switching on the resistive load and it becomes finite after this event. Further, it is also observed that the current waveform is uniform. Figure 6(c) illustrates that the current supplied by the micro-grid to the AC bus and DC current to the inverter (HRES current) have constant values with minimum disturbances in the on-grid mode. Hence, it can be concluded that in the offgrid mode, the proposed micro-grid works efficiently to supply the loads and additional power is absorbed by the battery which can be used as and when required to supply the load.
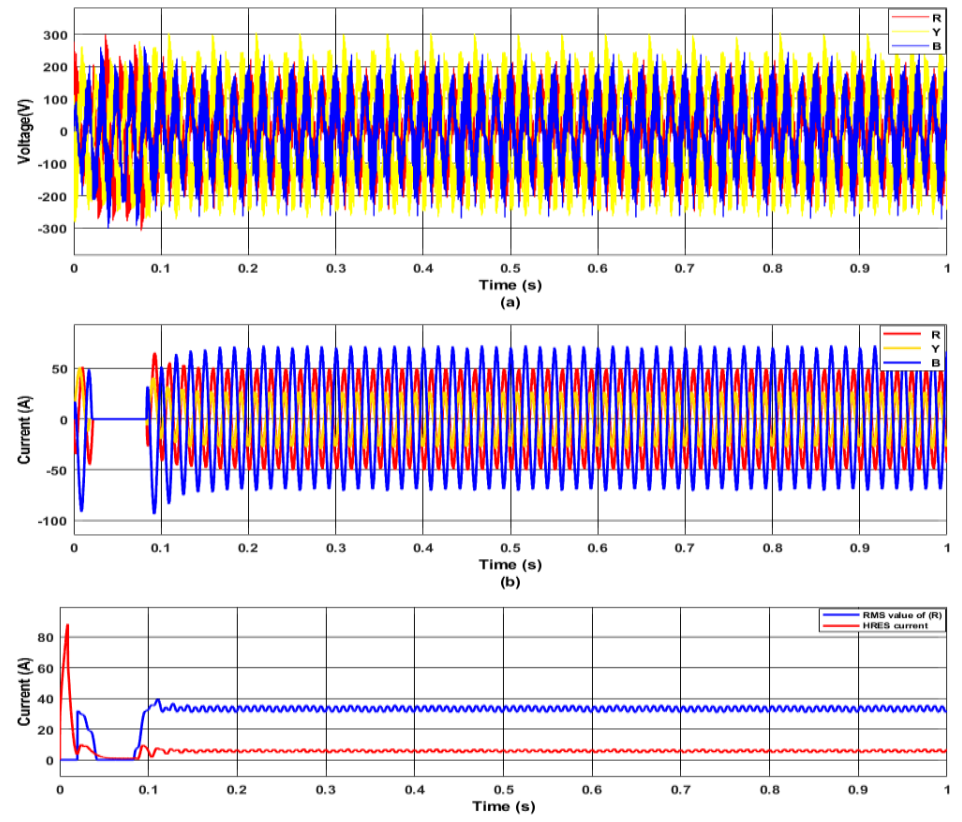

Figure 6. Micro-grid is operated in on-grid mode during event of switching on the resistive load: (a) voltage signal profile, (b) current signal, and (c) RMS value of current and HRE source current

\subsection{Event of switching on all the loads in off-grid mode}

The test micro grid is operated in off-grid mode to analyze the performance. The micro-grid test system is kept disconnected from the utility grid. All the loads are connected to the AC bus at $0.1 \mathrm{~s}$ to investigate the effect of switching off the active and reactive loads on performance of the proposed micro-grid in the offgrid mode. Power generated by the SOFC, power stored by the BESD, power generated by solar PV System and active and reactive power consumed by the loads are illustrated in the Figure 7. Figure 7(a) and Figure 7(b) indicate that the $45 \mathrm{~kW}$ and $6 \mathrm{~kW}$ power is supplied by the SOFC and solar PV system respectively. Figure 7(c) indicates that the power absorbed by the BESD is equal to $36 \mathrm{~kW}$. It is observed that from the Figure $7(\mathrm{~d})$ that $5 \mathrm{~kW}$ power on each phase (total $15 \mathrm{~kW}$ power) is consumed by the resistive load. The reactive power of $1.12 \mathrm{kVAr}$ is absorbed by the filter installed between the DC-AC inverter and AC bus. Therefore, it is established that when the test micro-grid is operated in the off-grid mode in the presence of active and reactive loads, the power supplied by the SOFC and solar PV system is used to charge the BESD and consumed by the resistive load. Hence, the proposed micro-grid system operates efficiently in the presence of the resistive and reactive loads in the off-grid mode.

The waveforms of voltage measured on the AC bus and current supplied by the micro-grid to the AC bus when Micro-grid is operated in off-grid mode during event of switching on all the loads are detailed in the Figures 8(a) and 8(b) respectively. The root mean square (RMS) value of the current supplied by the microgrid to the AC bus and DC current to the inverter (HRES current) are described in the Figure 8(a) and Figure 8 (b) respectively. The transients observed at starting time are due to the start of the simulation. Figure 8(c) 
illustrates the current signal and RMS value of the current \& HRE source current. Figure 8(a) illustrates that before switching on the load, there are small transients in the voltage which have been reduced after the resistive load is switched on at $0.1 \mathrm{~s}$. Figure 9(b) illustrates that current is zero before the event of switching on all the loads and it becomes finite after this event. Further, it is also observed that small magnitude transients are observed in the current waveform due to the presence of reactive loads. Figure 9(c) illustrates that current supplied by the micro-grid to the AC bus and DC current to the inverter (HRES current) have constant values with minimum disturbances in the off-grid. Hence, it can be concluded that in the off-grid mode the proposed micro-grid works efficiently to supply the active and reactive loads. The additional power is absorbed by the battery which can be used as and when required to supply the load.
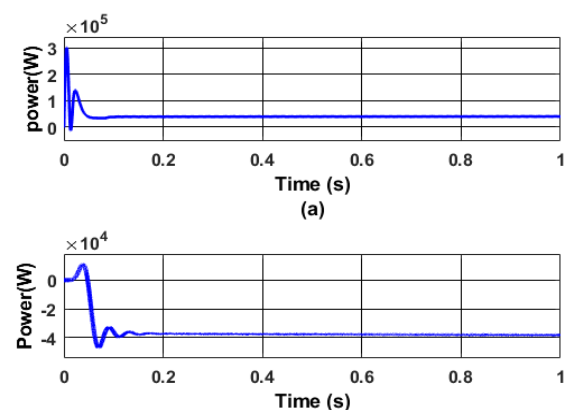

(b)

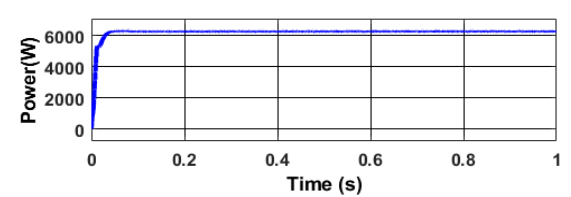

(c)

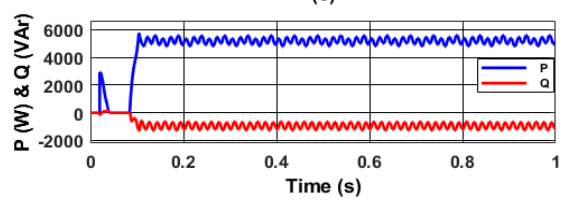

(d)

Figure 7. Micro-grid is operated in off-grid mode during event of switching on all the loads: (a) power generated by SOFC, (b) power stored by BESD, (c) power generated by solar PV system, and (d) active and reactive power exchange between the $\mathrm{AC}$ bus and $\mathrm{DC}$ bus

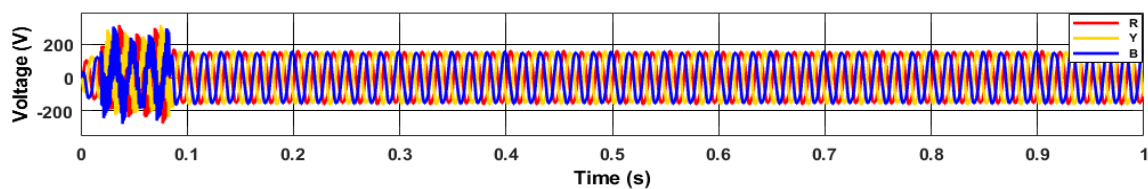

(a)
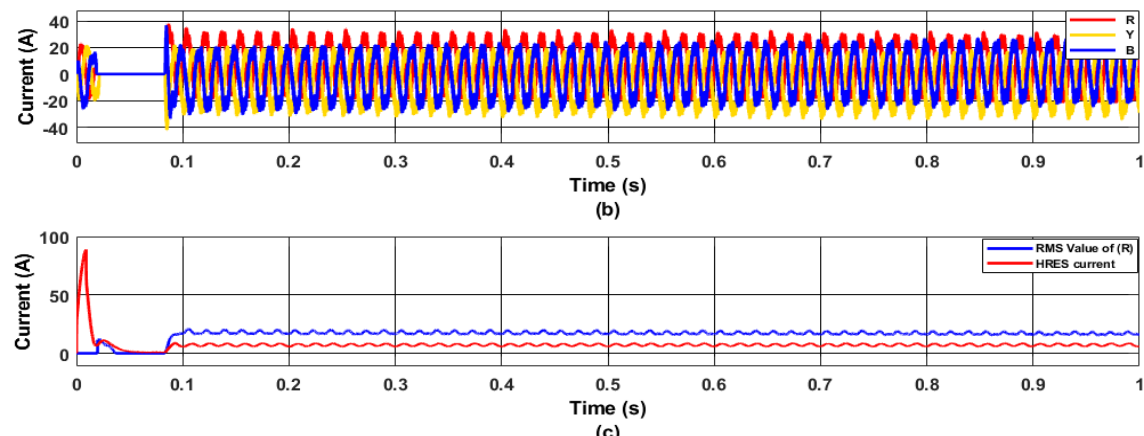

(c)

Figure 8. Micro-grid is operated in off-grid mode during event of switching on all the loads: (a) voltage signal, (b) current signal, and (c) RMS value of current and HRE source current

\subsection{Event of switching on all the load in on-grid mode}

The test micro grid is operated in on-grid mode to analyze the performance. The test micro-grid is kept connected to the utility grid. All the loads are connected to the AC bus at $0.1 \mathrm{~s}$ to investigate the effect of switching on the active and reactive loads on performance of the proposed micro-grid in the on-grid mode. Power generated by the SOFC, power stored by the BESD, power generated by the solar PV System and active $\&$ reactive power consumed by all the loads are illustrated in the Figure 9.

Figure 9(a) and Figure 9(b) indicate that the $45 \mathrm{~kW}$ and $6 \mathrm{~kW}$ power is supplied by the SOFC and solar PV system respectively. Figure 9(c) indicates that the power absorbed by the BESD is equal to $37.5 \mathrm{~kW}$. It is observed from the Figure 9 (d) that the $4.5 \mathrm{~kW}$ power $(13.5 \mathrm{~kW}$ three-phase power) is consumed by the resistive load. The reactive power of $1.12 \mathrm{kVAr}$ is absorbed by the filter installed between the DC-AC inverter 
and $\mathrm{AC}$ bus. Therefore, it is established that when the test micro-grid is operated in the on-grid mode in the presence of the active and reactive loads, the power supplied by the SOFC and solar PV system is used to charge the BESD and consumed by the resistive load. The balance $0.5 \mathrm{~kW}$ power has been supplied by the utility grid. Hence, the proposed micro-grid system operates efficiently in the presence of the resistive and reactive loads in the on-grid mode.
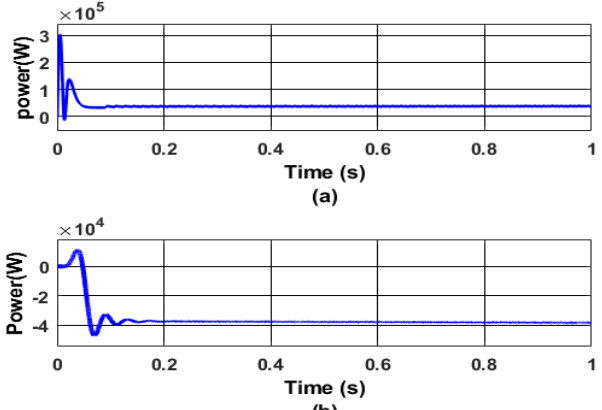

(b)

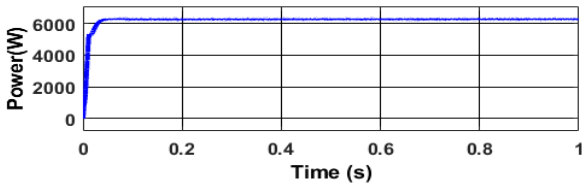

(c)

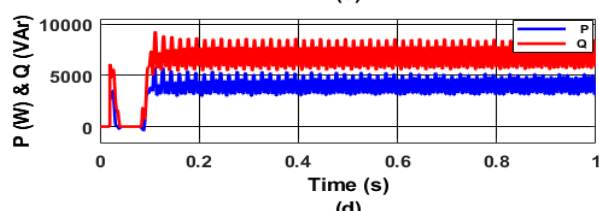

(d)

Figure 9. Micro-grid is operated in on-grid mode during event of switching on all the loads: (a) power generated by SOFC, (b) power stored by BESD, (c) power generated by solar PV system, and (d) active and reactive power exchange between the $\mathrm{AC}$ bus and $\mathrm{DC}$ bus

The waveforms of voltage measured on the AC bus and current supplied by the micro-grid to the AC bus during event of switching on the resistive load in on-grid mode are detailed in the Figures 10(a) and 10(b) respectively. The root mean square (RMS) value of the current supplied by the micro-grid to the AC bus and DC current to the inverter (HRES current) are described in the Figure 10(a) and Figure 10(b) respectively. The transients observed at the starting time are due to the start of the simulation. Figure 10(a) illustrates that before switching on the load, there are small transients in the voltage which have been reduced after the resistive load is switched on at 0.1s. Figure 10(b) illustrates that current is zero before the event of switching on the resistive load and it becomes finite after this event. Further, it is also observed that the current waveform is uniform. Figure 10(c) illustrates that the current supplied by the micro-grid to the AC bus and DC current to the inverter (HRES current) have constant values with minimum disturbances in the on-grid mode. Hence, it can be concluded that in the on-grid mode the proposed micro-grid works efficiently to supply the loads.
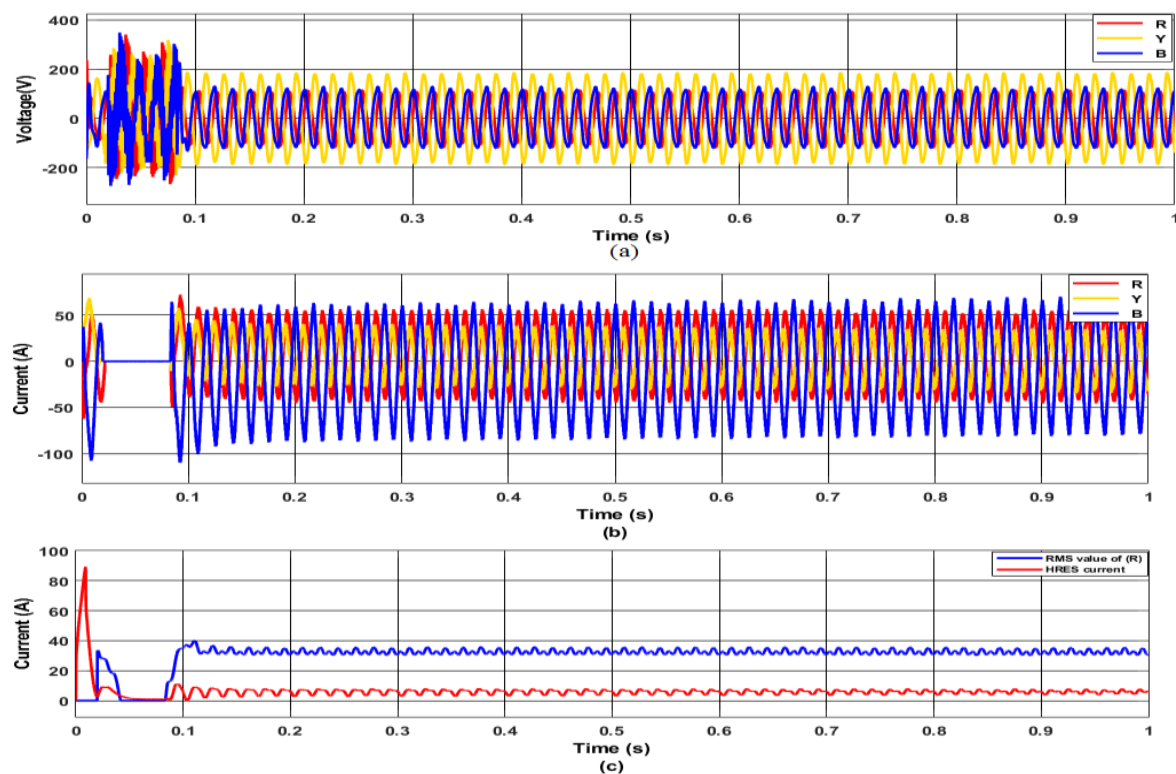

Figure 10. Micro-grid is operated in on-grid mode during event of switching on all the loads: (a) voltage signal, (b) current signal, and (c) RMS value of current and HRE source current

\section{COMPARATIVE PERFORMANCE}


Comparative performance of the proposed micro-grid during events of the switching on and off the active and reactive loads in both the on-grid and off-grid modes has been performed using the Total harmonic distortions of the voltage and current signals recorded at different buses of the micro-grid. CIP is introduced to indicate the effectiveness of the micro-grid operations in the off-grid mode. This CIP is computed by (4).

$$
C I P=\frac{T H D A G-T H D P G}{T H D A G} \times 100 \%
$$

Where THDPG indicates the THD in the on-grid mode (presence of utility network) operation of the micro-grid; THDAG indicates the THD in the off-grid mode (absence of utility network) operation of the micro-grid. The THD of voltage recorded on PCC of the test micro-grid in both the on-grid and off-grid modes of operations has been illustrated in the Table 5. It is observed from this table that the values of THD are the off-grid mode are comparable with the values recorded in the on-grid mode of operation of the micro-grid. Further, the values of the CIP are low. Hence, it is established that the proposed micro-grid efficiently works in both the on-grid modes during different events of load switching.

Table 5. THD in load voltage signal

\begin{tabular}{|c|c|c|c|}
\hline \multirow{2}{*}{ Name of Events } & \multicolumn{2}{|c|}{ THD (\%) } & \multirow{2}{*}{ CIP } \\
\hline & Without Grid & With Grid & \\
\hline Switching ON pure Resistive Load & 16.19 & 13.69 & 15.44 \\
\hline Switching ON all Resistive and Reactive Load & 17.01 & 13.87 & 18.46 \\
\hline Switching ON pure Reactive Load & 21.04 & 16.41 & 22 \\
\hline
\end{tabular}

The THD of current recorded on PCC of the test micro-grid in both the on-grid and off-grid modes of operations has been illustrated in the Table 6. It is observed from this table that the values of THD in the offgrid mode are comparable with the values recorded in the on-grid mode of operation of the micro-grid. Further, values of the CIP are low. Hence, it is established that the proposed micro-grid efficiently works in both the on-grid modes during different events of load switching.

Table 6. THD in load current signal

\begin{tabular}{|c|c|c|c|}
\hline \multirow{2}{*}{ Name of Events } & \multicolumn{2}{|c|}{ THD (\%) } & \multirow{2}{*}{ CIP } \\
\hline & Without Grid & With Grid & \\
\hline Switching ON pure Resistive Load & 16.01 & 6.04 & 62.27 \\
\hline Switching ON all Resistive and Reactive Load & 23.34 & 8.64 & 62.98 \\
\hline Switching ON pure Reactive Load & 25.18 & 17.04 & 32.32 \\
\hline
\end{tabular}

\section{CONCLUSION}

This research article presents a design of micro-grid to achieve the optimal mix of generation capacity from Solar PV system, Fuel-cell, Battery Energy Storage Device and Conventional Generators to Meet the Future Load Demand. All these green energy sources are integrated to common DC bus which is interfaced to the $\mathrm{AC}$ bus using an inverter. The variations in the power generation by one source have been mitigated on the DC bus by other generators. CIP is introduced to indicate the effectiveness of the micro-grid operations in the off-grid mode. It is concluded that proposed micro-grid model is effective to meet the load demand in the ongrid as well as off-grid mode. Further, CIP has values lower than $50 \%$ indicating that the level of current and voltage THDs have increased slightly in the off-grid mode compared to the on-grid mode. However, the microgrid works efficiently in both the on-grid and off-grid modes. Hence, the proposed optimal generation mix in the on-grid as well as off-grid mode has minimized the disturbances and variations of the network parameters.

\section{REFERENCES}

[1] O P Mahela, B Khan, H Hs Alhelou, P Siano, "Power Quality Assessment and Event Detection in Distribution Network with Wind Energy Penetration Using Stockwell Transform and Fuzzy Clustering," IEEE Transactions on Industrial Informatics, vol. 16, no. 11, pp. 6922-6932, 2020. doi: 10.1109/TII.2020.2971709.

[2] G S Chawda, A G Shaik, O P Mahela, S Padmanaban, J B Holm-Nielsen, "Comprehensive Review of Distributed FACTS Control Algorithms for Power Quality Enhancement in Utility Grid with Renewable Energy Penetration," in IEEE Access, vol. 8, pp. 107614-107634, 2020. doi: 10.1109/ACCESS.2020.3000931.

[3] M C Ghenai and M Bettayeb, "Grid-Tied Solar PV/Fuel Cell Hybrid Power System for University Building" Energy Procedia, vol. 159, pp. 96-103, Feb. 2019. doi: 10.1016/j.egypro.2018.12.025. 
[4] V Sharma and L Gidwani, "Minimization Impact of Grid Disturbances on performance of utility grid with wind energy penetration using battery energy storage devices," IEEE, 2019 International Conference on Computing, Power and Communication Technologies (GUCON), 2019.

[5] J Li,S Obara "Study on an energy supply system assuming a pipeline transportation of compressed hydrogen for distributed fuel cell in China," IEEE 10th International Symposium on Power Electronics for Distributed Generation Systems (PEDG), 2019.

[6] V Sharma, L Gidwani "Optimistic Use of DSTATCOM Controlled Battery Energy Storage System to Mitigate Grid Disturbances with Solar Energy Penetration," in 10th IEEE International Conference, India, 2019. doi: 10.1109/ICCCNT45670.2019.8944649.

[7] G S Chawda, O P Mahela, N Gupta, M Khosravy, T Senjyu, "Incremental Conductance based Particle Swarm Optimization Algorithm for Global Maximum Power Tracking of Solar-PV Under Nonuniform Operating Conditions," Applied Sciences, vol. 10, no. 13, pp. 4575, 2020. doi: 10.3390/app10134575.

[8] V Sharma and L Gidwani, "A Comprehensive Review: Energy Storage System for Hybrid System Including Wind Energy Generation System and Solar Energy Generation System for Utility Grid," Current Journal of Applied Science and Technology, vol. 21, no. 6, pp. 1-13, 2017. doi: 10.9734/CJAST/2017/34383.

[9] B Singh, P Jayaprakash, D Kothari, A Chandra, and K Al Haddad, "Comprehensive study of DSTATCOM configurations," IEEE Transactions on Industrial Informatics, vol. 10, no. 2, pp. 854-870, 2014. doi:10.1109/TII.2014.2308437.

[10] O P Mahela, B Khan, H H Alhelou, S Tanwar," Assessment of Power Quality in the Utility Grid Integrated with Wind Energy Generation," IET Power Electronics, vol. 13, no. 13, 2020. doi: 10.1049/iet-pel.2019.1351.

[11] A G Shaik and O P Mahela, "Power quality assessment and event detection in hybrid power system," Electric Power Systems Research (Elsevier), vol. 161, pp. 26-44, Mar 2018. doi: 10.1016/j.epsr.2018.03.026.

[12] G S Yogee, O P Mahela, K D Kansal, B Khan, Ra Mahla, H H Alhelou, P Siano, "An Algorithm for Recognition of Fault Conditions in the Utility Grid with Renewable Energy Penetration," Energies, vol. 13, no. 9, pp. 2383, 2020. doi: 10.3390/en13092383.

[13] O P Mahela, J Sharma, B Kumar, B Khan, H H Alhelou, "An Algorithm for the Protection of Distribution Feeder Using Stockwell and Hilbert Transforms Supported Features," CSEE Journal of Power and Energy Systems, pp. 1-9. doi: 10.17775/CSEEJPES.2020.00170.

[14] S R Ola, A Saraswat, S K Goyal, S. K. Jhajharia, B Rathore, O P Mahela, "Wigner Distribution Function and Alienation Coefficient Based Transmission Line Protection Scheme," IET Generation, Transmission and Distribution, vol. 14, no. 10,pp. 1842-1853, May 2020. doi: 10.1049/iet-gtd.2019.1414.

[15] S R Ola, A Saraswat, S K Goyal, V Sharma, B Khan, O P Mahela, H H Alhelou, P Siano, "Alienation Coefficient and Wigner Distribution Function Based Protection Scheme for Hybrid Power System Network with Renewable Energy Penetration," Energies, vol. 13, no. 5, pp. 1120, Mar 2020. doi: 10.3390/en13051120.

[16] O P Mahela, and Al G Shaik, "Comprehensive Overview of Grid Interfaced Solar Photovoltaic Systems," Renewable and Sustainable Energy Reviews (Elsevier), vol. 68, part 1, pp. 316-332, Feb 2017. doi: 10.1016/j.rser.2016.09.096.

[17] V Sharma., L Gidwani, "Frequency regulation of grid with wind power using Energy Storage System," International Journal of Grid Distributed and Computing, vol. 8, no. pp. 267-274, 2015. doi: 10.14257/ijgdc.2015.8.3.26.

[18] O P Mahela, and A G Shaik, "Power Quality Improvement in Distribution Network using DSTATCOM with Battery Energy Storage System," International Journal of Electrical Power and Energy Systems (Elsevier), vol. 83, no. 16, pp. 229-240, De 2016. doi: 10.1016/j.ijepes.2016.04.011.

[19] O P Mahela, P Gupta, S Ali, N Gupta, "Power Quality Improvement in Renewable Energy Sources Based Power System Using DSTATCOM Supported by Battery Energy Storage System," 5th IEEE International Conference on Electrical Energy Systems (ICEES 2019), Feb 2019. doi: 10.1109/ICEES.2019.8719318.

[20] V Sharma and L Gidwani "Optimistic Use of Energy Storage System to Mitigate Grid Disturbances in the Hybrid Power System,” AIMS Energy, vol. 7, no. 6, pp. 688-709, 2019. doi: 10.3934/energy.2019.6.688. 